\title{
¿Qué hacer con los influencers?
}

\author{
Alex Sosa Huapaya \\ Abogado por la Universidad de Lima. \\ Magíster en Derecho de la Propiedad Intelectual y de la \\ Competencia por la Pontificia Universidad Católica del Perú. \\ Profesor de la Universidad Científica del Sur. \\ Ex Secretario Técnico del Consejo Nacional de \\ Autorregulación Publicitaria.
}

SUMARIO:

I. Introducción.

II. Definiendo a los influencers: ¿es necesario hacerlo?

III. ¿Todos los actos de los influencers están sujetos a la LRCD?

IV. ¿El uso de influencers es publicidad encubierta?

V. Cuando el influencer es utilizado en publicidad testimonial.

VI. ¿El influencer va a ser sancionado con hasta 700 UIT?

VII. Tips para usar influencers.

1. Tip $\mathrm{N}^{\circ} 1$ : mantener bajo control al influencer.

2. Tip $\mathrm{N}^{\circ} 2$ : el uso de hashtags.

3. Tip $\mathrm{N}^{\circ}$ 3: el uso de instastories y live stream para hacer publicidad con influencers.

VIII. Cuando el influencer es a la vez el anunciante.

IX. Reflexión final. 


\section{RESUMEN:}

En este artículo, el autor desarrolla la regulación relacionada a la publicidad de influencers. En este sentido, concluye que dicha publicidad no es otra cosa más que una nueva forma de hacer publicidad testimonial y que la posibilidad de que se trate de publicidad encubierta es bastante menor.

Palabras clave: influencers, INDECOPI, publicidad , competencia desleal, publicidad testimonial, engaño.

\footnotetext{
ABSTRACT:

In this article, the author develops the regulation related to advertising by influencers. In this sense, he concludes that said advertising is nothing more than a new way of doing testimonial advertising and that the possibility of dealing with concealed advertising is quite minor.

Keywords: influencers, INDECOPI, advertising, unfair competition, endorsements and testimonials in advertising, deception.
}

\section{INTRODUCCIÓN}

Se ha hablado mucho durante este año acerca de los influencers o "generadores de contenido" - como le gusta que los llamen — tanto a nivel nacional como internacional, pues el uso de los mismos por parte de los anunciantes ha sido calificado muchas veces como desleal al tratarse, supuestamente, de publicidad encubierta; y se han esbozado diversas formas de tratar de detener, poner freno o controlar a este "fenómeno" que de nuevo no tiene nada y que no es más que un poco de "humo" sobre lo que ya existe — solo que utilizando redes sociales-.

Como es de conocimiento público, a mediados del 2019 se difundieron algunas noticias en los diarios acerca de la posibilidad que se regule a los influencers o que estos podrían ser sancionados con hasta 2,9 millones de Soles -700 UIT-Unidades Impositivas Tributarias-, lo cual evidentemente encendió todas las alarmas de los anunciantes que hacen uso de ellos y de los propios influencers. Pero como si esto no fuera poco, en el mes de octubre de 2019, el Instituto Nacional de Defensa de la Competencia y de la Protección de la Propiedad Intelectual —INDECOPI- emitió una "Guía sobre publicidad digital y recomendaciones para influencers", que si bien hasta la fecha de la redacción del presente artículo sigue en revisión, se publicó con varios desaciertos que podrían, de permanecer en la versión final de la guía, perjudicar a los anunciantes en el uso de una herramienta publicitaria completamente lícita'.

De este modo, el propósito de este artículo es analizar si el uso de influencers es publicidad encubierta y qué tan peligroso puede ser para el correcto funcionamiento del mercado. Además, se brindarán algunos consejos para los anunciantes, empresas y, sobre todo, para generadores de contenido. Así, el esquema de este trabajo es el siguiente: (a) primero, abordaremos la supuesta "nueva regulación" que se dice recaerá sobre los influencers; luego, (b) se desarrollarán algunos tips para no ser sancionado por publicidad encubierta - si es que esta es posible-; y, finalmente, (c) consejos para anunciantes a fin de que puedan usar influencers en publicidad testimonial.

\section{DEFINIENDO A LOS INFLUENCERS: ¿ES NE- CESARIO HACERLO?}

En este punto preocupan las definiciones de influencers con las que pretende "jugar" la guía que publicó el INDECOPI para comentarios, toda vez que la misma lo define como "persona

1. Es importante precisar que el presente artículo se presentó en noviembre de 2019, antes de que se publique la versión final de la guía de publicidad para influencers del INDECOPI. 
que cuenta con cierta credibilidad sobre un tema determinado y que, dada su capacidad de convencimiento o llegada a sus seguidores, sin tener en consideración necesariamente el número de estos puede convertirse en un componente determinante en las decisiones que los consumidores realizan en el mercado".

Siguiendo dicha definición, nos preguntamos, ¿qué sucede si dicho influencer no cuenta con credibilidad sobre el producto que hace publicidad, pero es tan famoso que sí puede generar un incremento de persuasión en la comunicación? ¿ya no encaja en la definición?

Consideramos que el problema radica en tratar de encontrarle una nueva definición a una figura que nos ha acompañado prácticamente desde que existe la publicidad comercial: el uso de testigos en anuncios o la publicidad testimonial. Salvo las diferencias en los mecanismos y formas de comunicación que utilizan, el influencer no es más que una herramienta publicitaria utilizada por el anunciante para reforzar el nivel de persuasión de su marca, cuya particularidad es que en la mayoría de los casos se realizará dicha publicidad testimonial a través de la cuenta de la red social del influencer, el cual realizará un unboxing, canje, sorteo, o simplemente recomendará el uso del producto o servicio.

Luego, consideramos que es completamente incorrecto afirmar que para ser influencer, este personaje debe ser un "componente determinan- te en las decisiones que los consumidores realizan en el mercado". Y es que entender el uso de este recurso publicitario de esa forma es creer que la publicidad comercial nos obliga a comprar productos o servicios del anunciante y que los consumidores solo son borregos que hacen lo que el influencer les dice. Nada más lejano de la realidad. La publicidad, por definición -incluso en la definición de la Ley de Represión de la Competencia Desleal — LRCD—, es susceptible de generar como efecto el persuadir a los consumidores a realizar determinada transacción económica a favor del anunciante. No lo obliga a comprar un producto ni usando al influencer más simpático o carismático del medio².

¿Quiénes son los influencers? Digamos, de modo bastante general, que los influencers son líderes de opinión en redes sociales, que manejan una gran cantidad de seguidores por la fama que poseen en el entorno digital y pueden ser utilizados por los anunciantes como herramientas publicitarias. Nada más que eso. No condicionan decisiones de consumo, son parte de la publicidad comercial -en una especie de publicidad testimonial digital-. Dejemos de inventar conceptos si se pueden adaptar a los que ya tenemos - recomendamos revisar las definiciones del artículo 59 de la LRCD, sobre todo, detenerse en publicidad testimonial $y$ testigos ${ }^{3}$ -

Establecer diferencias entre las definiciones de publicidad testimonial o testigos en la publici-

2. Luego de esbozar tan mala definición de los "generadores de contenido", el proyecto de guía define la "publicidad de influencers" como "prácticas realizadas por el influencer destinadas a promover, directa o indirectamente las marcas, productos o servicios del anunciante, siempre y cuando se hayan originado como consecuencia del contacto previo del anunciante a cambio de un pago o beneficio de cualquier tipo." Sin embargo, el INDECOPI no se detiene a pensar que un tipo de publicidad del influencer, es también cuando el propio influencer es el anunciante, así que no es tan exacta esta definición. En todo caso, la figura a definir sería "publicidad que hace el influencer a favor de terceros".

3. Sobre la publicidad testimonial, el artículo 58 de la LRCD nos alcanza las siguientes definiciones:

\footnotetext{
j) Publicidad testimonial: a toda publicidad que puede ser percibida por el consumidor como una manifestación de las opiniones, creencias, descubrimientos o experiencias de un testigo, a causa de que se identifique el nombre de la persona que realiza el testimonial o ésta sea identificable por su fama o notoriedad pública;

(...)

i) Testigo: a toda persona natural o jurídica, de derecho público o privado, distinta del anunciante, cuyas opiniones, creencias, descubrimientos o experiencias son presentadas en publicidad.
} 
dad y los influencers generaría como consecuencia que el INDECOPI tenga que hacer diferencias cuando Cristiano Ronaldo, por ejemplo, sea utilizado como testigo en publicidad comercial del shampoo EGOMEN y cuando desde su cuenta de Instagram haga publicidad a favor de la misma marca. ¿En el primer caso solo sería parte de la publicidad y en el segundo prácticamente obligaría a los consumidores a comprar el producto por su nivel de influencia e impacto - esto según las definiciones que se ensayan en la guía- $?^{4}$

\section{III. ¿TODOS LOS ACTOS DE LOS INFLUENCERS ESTÁN SUJETOS A LA LRCD?}

Empezamos por la parte que viene generando un poco de miedo o terror: la supuesta nueva regulación para los influencers. Ciertamente, se difundieron algunas noticias de diarios importantes del país cuyos titulares decían lo siguiente: "Indecopi da pautas para que se eviten multas de hasta 2.9 millones de soles", "Indecopi: Influencers podrán ser multados por publicidad engañosa", entonces, este asunto está poniendo bastante nerviosos a los influencers y a los anunciantes que hacen uso de ellos, así que vamos a despejar estas dudas.

Todas esas noticias son falsas. Los actos concurrenciales de los influencers están regulados y, podemos decirlo, desde antes de su nacimiento, pues la LRCD es completamente aplicable para los influencers como también para los anunciantes y acá no hay nada nuevo, no existe la más remota posibilidad - espero- de una nueva regulación ni nada por el estilo que pueda recaer sobre la actividad de estos divertidos e interesantes personajes.

Ahora bien, la pregunta cae de madura: ¿la norma aplica para todos los actos que realicen los influencers? Y la respuesta es un rotundo no. La LRCD solo aplica para los actos que tengan finalidad concurrencial. ¿Y qué significa esto? La Sala de Defensa de la Competencia ha señalado en reiterados pronunciamientos que:

\section{“(..) un comportamiento tendrá finalidad concurrencial cuando a través de su reali- zación, el agente económico que lo comete, procura obtener algún tipo de ventaja en un determinado segmento competitivo. En ese sentido, serán actos concurrenciales todas aquellas actividades dotadas de trascen- dencia externa, esto es, que se ejecuten en el mercado y, que sean susceptibles de mante- ner o incrementar el propio posicionamiento comercial de quien que lo realiza." ${ }^{5}$}

De este modo, si un día un influencer publica en sus instastories un recuerdo de una obra teatral de la cual participó o publica una foto suya con un maquillaje particular sin mostrar una marca comercial de por medio, ¿eso es un acto con finalidad concurrencial? Evidentemente no. Dichas publicaciones no son susceptibles de mejorar la posición concurrencial de dicha influencer ni la de una empresa anunciante. Dichas publicaciones están protegidas por la libertad de expresión. Está haciendo un uso completamente libre de sus redes sociales.

¿Qué acto en el que participe el referido influencer sí podría tener finalidad concurrencial? Les damos un par de ejemplos: (a) si la empresa $X$ utiliza la imagen de un influencer para que recomiende ciertos productos de la empresa o utiliza su imagen dentro de su publicidad comercial —en estos casos el anunciante sería $X$ y el uso del influencer en su publicidad sería un acto con finalidad concurrencial, pero del anunciante-; y, (b) si dicho influencer desarro-

4. Consideramos que el problema de todo esto radica en que estamos partiendo de la premisa que los influencers son "malos" o que su existencia es negativa. Nuestra hipótesis se confirma cuando el proyecto de guía cita un documento del 2005 de la Unión Europea para sustentar que los influencers distorsionan el comportamiento económico del consumidor, pues prácticamente lo obliga a tomar una decisión que no habría tomado en su sano juicio. ¿Tanta influencia generan?

5. Resolución Nº065-2018/SDC-INDECOPI. 
lla su propia marca de ropa - por ejemplo-y los promociona a través de sus redes sociales -en este último caso este sería el anunciante y el acto con finalidad concurrencial le generaría un beneficio directo-.

Para entender la diferencia establecida en los párrafos anteriores, es importante tener claro que para que un acto tenga finalidad concurrencial, deben concurrir dos requisitos: (a) que ese acto tenga efectos en el mercado, y el segundo requisito es que (b) ese acto sea susceptible de mejorar la posición concurrencial o en el mercado del agente económico que lo practica — de manera directa o indirecta-. Si el acto no tiene finalidad concurrencial no se le aplica la LRCD, de conformidad con lo establecido en el artículo 2 de la referida norma ${ }^{6}$.

Así, podemos afirmar con total seguridad que, todo tipo de publicidad comercial siempre tiene finalidad concurrencial, ¿por qué? porque siempre va a impactar o tener un efecto en el mercado - si se difunde o exterioriza - y siempre va a generar la posibilidad de que mejore la posición concurrencial del anunciante en el mercado, así venda un solo producto.

Esta explicación es de gran utilidad para los influencers, pues permite hacerles entender que cada vez que hagan publicidad para una marca o sobre sus propios productos o eventos, tienen que cumplir con lo que dice la LRCD, que no solamente se limita al principio de autenticidad o disposiciones sobre publicidad testimonial, pues incluye todas las modalidades desleales contenidas en la norma y cualquier otra que pueda tratarse de un acto contrario a la competencia por eficiencia.

¿Qué actos de los influencers tendrán finalidad concurrencial? Digamos que con los dos con los que por lo general se presentan al mercado:

a) Como soporte publicitario o testimonio para terceros anunciantes, es decir, un anunciante utiliza al influencer para que, a través del uso de su cuenta de red social, emita ciertos comentarios, comparta su experiencia respecto al producto, lo luzca puesto, lo use o simplemente, haga un unboxing. También el anunciante puede utilizar al influencer como testigo en su propia publicidad — de tipo testimonial一, situación en la que tendremos al influencer fuera de su cuenta y lo tendremos inserto en la publicidad comercial del anunciante.

b) Cuando el influencer es a la vez, anunciante, en estos casos vemos que este desarrolla su propia línea de productos o servicios y los promociona. Y es algo natural, pues llega el punto en el que el influencer se da cuenta que es tan famoso que puede no solamente recomendar ciertas marcas sino crear su propia marca.

A este punto, nos debe quedar bastante claro que los influencers van a tener este tipo de participación en el mercado: o bien son usados en o para hacer publicidad a favor de terceros o son anunciantes. Y cuando lo hagan, dichos actos tendrán finalidad concurrencial por lo que la LRCD le es completamente aplicable. Cualquier otro tipo de acto distinto que carezca de finalidad concurrencial no se encuentra sujeto a la norma.

\section{IV. ¿EL USO DE INFLUENCERS ES PUBLICIDAD ENCUBIERTA?}

La publicidad encubierta ${ }^{7}$ se encuentra regulada por el principio de autenticidad contenido en el

6. Artículo 2.-Ámbito de aplicación objetivo.-

La presente Ley se aplica a actos cuyo efecto o finalidad, de modo directo o indirecto, sea concurrir en el mercado. Se incluyen bajo la aplicación de esta Ley los actos realizados a través de publicidad. En ningún caso es necesario determinar habitualidad en quien desarrolla dichos actos.

7. Según Anxo Tato "(...) la publicidad encubierta surge, así pues, cuando el mensaje publicitario no ha sido identificado 
artículo 16 del Decreto Legislativo 1044. ¿Qué es lo que busca reprimir el referido principio? Busca reprimir que los anunciantes usen como estrategia de marketing, comunicaciones comerciales que no permitan que el consumidor diferencie $o$ entienda su naturaleza publicitaria ${ }^{8}$.

¿Cuál es el principal problema de la publicidad encubierta? El principal problema de esta modalidad publicitaria es que puede generar como efecto que el consumidor crea que la comunicación a la cual se encuentra expuesto es información imparcial y objetiva, cuando ello no es cierto.

¿Y cuál es el fundamento de esta protección? Es bastante simple, ¿ustedes creen todo lo que les dice la publicidad? Evidentemente no. El punto es que tendemos a ser relativamente escépticos cuando estamos frente a la publicidad comercial, no nos creemos todo lo que nos dice el anunciante, porque sabemos que nos están tratando de vender algo y que, por ello, nos van a hablar maravillas del producto. Recordemos que ello es la esencia de la publicidad comercial, pues su finalidad es persuadir a los receptores a fin de que realicen transacciones comerciales a favor del anunciante. De este modo, nos ponemos cierto escudo o barrera cuando estamos expuestos a la publicidad comercial, lo cual nos permite ser más diligentes y recurir a otras fuentes de información para obtener más detalles sobre las condiciones y particularidades del producto o servicio que deseamos adquirir.
En efecto, somos relativamente escépticos a la publicidad comercial. Queremos, por lo general, informarnos un poquito más antes de tomar una decisión. Si vemos letras pequeñas por ahí, decimos "acá puede haber gato encerrado". Por otro lado, ¿se han preguntado cuál es nuestra reacción frente a documentales, entrevistas, notas periodísticas, reportajes?; es completamente distinta, ya que tendemos a creer un poco más en ellas, ¿por qué? Porque creemos que son objetivas, que nacen de una investigación, que no están parcializadas a favor de una marca, que son completamente imparciales.

Entonces, existen algunos anunciantes maliciosos que utilizan estas figuras para de alguna manera ocultar el carácter comercial de una comunicación y de esta forma hacer que el consumidor crea un poco más en el mensaje publicitario. Así, lo que busca reprimir el principio de autenticidad son este tipo de comunicaciones, reprimir la publicidad encubierta. Sin embargo, es importante precisar que dicho principio brinda una solución a los anunciantes por si desean difundir publicidad que pueda generar el riesgo de que el consumidor no entienda o perciba su naturaleza comercial: establece que se puede emitir este tipo de comunicaciones siempre y cuando se advierta que se trata de un anuncio contratado o un publirreportaje?

Una vez dicho todo lo anterior y teniendo claro qué es la publicidad encubierta ${ }^{10}$, es importante preguntarnos cómo el INDECOPI puede determinar cuándo un influencer está haciendo

como tal y su finalidad publicitaria tampoco es reconocible por el público de los consumidores. Podríamos hablar entonces, quizás, de publicidad oculta o publicidad disfrazada, en la medida en que el correspondiente mensaje se presenta ante los ojos de los consumidores, bien bajo la apariencia de un mensaje informativo, bien bajo el disfraz de un mensaje de cualquier otra naturaleza. De donde se deduce que, en la hipótesis de la publicidad encubierta, existe un engaño del público en punto a la naturaleza y finalidad del correspondiente mensaje; al ignorar la naturaleza publicitaria de éste, el público podrá concluir que se encuentra ante un mensaje puramente informativo (...) o ante un mensaje justificado únicamente por criterios artísticos."

Anxo Tato Plaza, «Product Placement y publicidad encubierta (comentario a las Resoluciones del Jurado de Autocontrol de la Publicidad de 26 de abril y de 4 de junio de 2001, caso "soberano"», Actas de Derecho Industrial, n XXII (2001): 585-586.

8. Alex Sosa, «La publicidad encubierta y nuevas modalidades publicitarias», Revista de Actualidad Mercantil, n. 4 (2016): 252-266, http://revistas.pucp.edu.pe/index.php/actualidadmercantil/article/view/14964/15498. 
publicidad o no. $Y$ es que este es el punto de controversia de usar influencers para que promocionen marcas de terceros en su cuenta de cualquier red social: ¿cómo saber si es publicidad encubierta o no?, ¿si es publicidad o si es parte de una comunicación cualquiera? Es una tarea compleja, pero que igual tiene una solución, la misma que ha sido desarrollada por el INDECOPI a través de su jurisprudencia. En efecto, hace más de 5 años la autoridad se pronunció sobre si el product placement configuraba publicidad encubierta ${ }^{11}$ y dicho criterio es completamente aplicable en la actualidad ${ }^{12}$.

De acuerdo con la Sala Especializada en Defensa de la Competencia de INDECOPI, deben presentarse de forma concurrente 2 factores para que estemos hablando de publicidad o para poder encontrar o determinar si esa publicidad es encubierta o no. La concurrencia de un factor objetivo más un factor subjetivo. El factor objetivo no es otra cosa que la existencia de una contraprestación - de cualquier tipoentre el anunciante y el influencer - no solo dinero, puede ser un canje, pueden ser viáticos, puede ser un carro, una casa, etc., en resumen, cualquier tipo de pago-.

Por su parte, el factor subjetivo se va a presentar cuando se muestre de forma destacada la marca o producto que quieren promocionar. Si se dan esos dos factores al mismo tiempo, estamos frente a publicidad comercial, pero si de pronto no existe el factor objetivo, o sea, si es que no hay ningún tipo de contraprestación, no hay canje, no hay absolutamente nada ni siquiera contacto entre el anunciante y el influencer, por más que este muestre de manera destacada la marca, no es publicidad comercial - así tenga efectos comerciales que le reporten mejoras a la marca promocionada- y el titular de la marca promocionada no será responsable de lo que pueda decir el influencer, pues no calificará como anunciante.

La situación descrita puede generar un efecto publicitario a favor del anunciante o en contra quizá, pero el anunciante no ha contratado con el influencer para generarse este beneficio. Si es que no existe este factor objetivo, si es que no existe ningún tipo de contraprestación entre el titular de la marca y el influencer — de cualquier tipo-, la comunicación realizada por este último forma parte de su derecho a la libertad de expresión y de ninguna manera genera que el titular de la marca sea anunciante, pues recuerden que por definición -incluida en el artículo 59, inciso c, de la LRCD—, anunciante es:

"(...) toda persona, natural o jurídica, que desarrolla actos cuyo efecto o finalidad directa o indirecta sea concurrir en el mercado y que, por medio de la difusión de publicidad, se propone: i) ilustrar al pú-

9. Artículo $16^{\circ}$.- Actos contra el principio de autenticidad.-

16.1.- Consisten en la realización de actos que tengan como efecto, real o potencial, impedir que el destinatario de la publicidad la reconozca claramente como tal.

16.2.- Constituye una inobservancia a este principio difundir publicidad encubierta bajo la apariencia de noticias, opiniones periodísticas o material recreativo, sin advertir de manera clara su naturaleza publicitaria. Es decir, sin consignar expresa y destacadamente que se trata de un publirreportaje o un anuncio contratado.

10. Sobre el principio de autenticidad, la Exposición de Motivos de la LRCD establece que: "(...) los actos contrarios al principio de autenticidad no se agotarían en la publicidad encubierta bajo la apariencia de noticias, opiniones periodísticas o material recreativo, sino que podrían configurarse mediante otro tipo de actos de naturaleza publicitaria que no sean percibidos por los consumidores como tales, incluido el eventual supuesto de la publicidad subliminal".

11. Cfr.: Resolución N³665-2012/SDC-INDECOPI.

12. Cabe precisar que, se designa product placement o "emplazamiento de producto", a la presentación, por cualquier medio, y con fines publicitarios, de productos o servicios, o de sus marcas o signos distintivos, durante el desarrollo de películas, series o cualquier otro programa difundido a través de medios de comunicación audiovisual. 
blico, entre otros, acerca de la naturaleza, características, propiedades o atributos de los bienes o servicios cuya producción, intermediación o prestación constituye el objeto de su actividad; o, ii) motivar transacciones para satisfacer sus intereses empresariales; (...)."

Ahora bien, lo que corresponde preguntarnos es si realmente los "posteos" de los influencers son tan peligrosos por tratarse de publicidad encubierta. ¿Somos tan ingenuos de pensar que cuando un influencer hace un unboxing, un sorteo o nos recomienda usar un producto, lo hace de voluntad propia sin obtener nada a cambio? Al parecer sí, pues es lo que le preocupa al INDECOPI y a diversas autoridades en el mundo, pero no creemos que ello sea correcto, por el contrario, consideramos que en la gran mayoría de casos es bastante evidente que dichos "posteos" sean publicidad comercial.

Si bien no negamos que en algunos casos sí se pueda presentar el riesgo de publicidad encubierta en la que se use a influencers, lo cierto es que en la mayoría de casos es poco probable, toda vez que las marcas y productos se van a mostrar de forma destacada y si de pronto, como es habitual, hay canjes, sorteos, unboxing o "taggeos" a las marcas, el consumidor va a notar que se trata de publicidad comercial, ya que no es tan ingenuo como para creer que un influencer - que vive justo de eso- se va a dedicar a recomendarle marcas y productos en nombre de la "paz mundial". Ciertamente, esto va a depender mucho del mercado en el que se realice la publicidad de influencers. Así, no nos queda duda que, si es uno de moda, maquillaje, restaurantes, alimentos, en suma, mercados de productos de consumo masivo, será mucho más fácil no entrar en la controversia de saber si es o no publicidad. Sin embargo, en los mercados más especializados sí podría generarse un riesgo de publicidad encubierta, sobre todo si se hace uso de influencers que tengan una relación de especialidad con el producto que promocionan. Por ejemplo, influencers en tecnología, que hacen comparativos entre celulares. Podrían estar siendo financiados por una empresa y se incrementaría el riesgo de que el consumidor no pueda advertir la naturaleza comercial y parcializada de la afirmación.

En el año 2014, Gustavo Rodríguez y el autor del presente artículo comentábamos que no considerábamos publicidad encubierta el uso testimonios en redes sociales - cuando en ese entonces aún no se acuñaba el término "influencer" y se hablaba de "tuits publicitarios"—:

"Existe una actual preocupación a nivel doctrinario acerca de si los tuits patrocinados configuran publicidad encubierta. Para los legisladores españoles cuando el tuit tenga naturaleza publicitaria y esta no sea evidente por su contexto, se estará frente a una clara publicidad encubierta a no ser que se indique su naturaleza comercial.

\section{(...)}

De este modo, los anunciantes que desean hacer uso de tuits patrocinados actualmente hacen uso de los hashtag \#ad —en Reino Unido los anunciantes consensuaron ello- o \#publi. Esta útima indicación en virtud de lo dispuesto en el artículo 20.1 de la Ley de Servicios de la Sociedad de la Información y de Comercio Electrónico, que en realidad se pensó exclusivamente para correos electrónicos comerciales.

Si bien en el Perú estos tuits patrocinados estarían sujetos a lo señalado en el artículo 16 de la $L R C D$ - y también del 8.2, publicidad testimonial-, nosotros consideramos que ello sería absurdo, pues por el contexto en el que se publican este tipo de anuncios, resultará obvio para cualquier consumidor que dichos tuits tienen naturaleza publicitaria, por lo que sería totalmente innecesario detallar que estos son anuncios contratados. ${ }^{\prime \prime 3}$

13. Alex Sosa y Gustavo Rodríguez, Con licencia para anunciar. Un tratado del Derecho Publicitario en el Perú (Lima: Themis, 2014), 108. 
De este modo, consideramos que la guía bajo análisis ha sido mal enfocada, toda vez que parece insinuar que la publicidad de influencers siempre va a ser encubierta, cuando en la mayoría de los casos, el consumidor podrá advertir la naturaleza comercial de la recomendación del influencer.

\section{CUANDO EL INFLUENCER ES UTILIZADO EN PUBLICIDAD TESTIMONIAL}

La forma usual en la que los anunciantes hacen uso de los influencers es la publicidad testimonial $^{14}$. Esto no tiene nada de novedoso. En toda la historia de la publicidad, los anunciantes han utilizado figuras como John Travolta, Sylvester Stallone, Christina Aguilera, Michael Jackson, entre otros famosos personajes como testigos en su publicidad ${ }^{15}$. Y en estos tiempos la situación no ha cambiado ni tendría por qué hacerlo. Así vemos que los anunciantes nacionales contratan a Mafer Neyra para que recomiende un local para el tratado del cabello después de un laceado y también podemos ver, a nivel internacional, a Dulceida en la publicidad de Huawei recomendando sus equipos celulares.
Estaremos frente a publicidad testimonial cuando se utiliza un testigo para compartir una experiencia y/o para trasladar su imagen comercial a favor de la marca o producto, lo cual es completamente lícito de acuerdo con nuestra LRCD, que lo único que le exige al anunciante que va a hacer uso de esta modalidad publicitaria es que cuente con las pruebas que acrediten que el testigo tuvo una experiencia auténtica y reciente con el producto ofertado ${ }^{16}$.

Así, si eres una empresa anunciante y vas a hacer uso de publicidad testimonial y tienes pensado utilizar influencers, jtodo bien!, pero debes asegurarte de contar con las pruebas de que dicho influencer ha tenido una experiencia auténtica y reciente con el producto o servicio que deseas promocionar.

Para probar ello no son suficientes las declaraciones juradas, de hecho, ya hay pronunciamientos recientes de la Sala Especializada en Defensa de la Competencia de INDECOPI que señalan que una declaración jurada de testigo no es prueba suficiente para acreditar que se trata de una experiencia auténtica reciente.

14. Según De La Cuesta:

\begin{abstract}
"se llama publicidad testimonial a aquella que en sus mensajes se hace aparecer a una persona o entidad diferente del anunciante expresando una opinión favorable acerca de éste o de sus productos o servicios.

Lo característico de la publicidad testimonial es que busca el refuerzo que supone que el mensaje se respalde por alguien distinto del anunciante, porque así se diluirán en el momento decodificador las consecuencias del carácter de mensaje interesado propio de todo mensaje de publicidad.

Congruentemente, la publicidad testimonial implica que la persona del testimoniante emita su opinión o parecer relativo a circunstancias integrantes del mensaje; también implica que el testimoniante aparezca como alguien enteramente diferente del anunciante. La forma de expresión de la publicidad testimonial puede ser muy variada, por ejemplo, mediante la inserción de cartas de agradecimiento de usuarios de producto, o de las buenas críticas de una buena película, etc.
\end{abstract}

La finalidad que se persigue con la publicidad testimonial y el bien al que ésta se refiere hacen que en la práctica aparezcan como testimoniantes personas que gozan de fama o celebridad entre el público, o expertos en la materia a que la publicidad se refiere, o personas comunes con experiencia por usar o consumidor el producto o servicio".

José María De La Cuesta Ruta, Curso de Derecho de la Publicidad (Navarra: EUNSA, 2002), 162.

15. Nuestra LRCD define al "testigo" de la siguiente manera: a toda persona natural o jurídica, de derecho público o privado, distinta del anunciante, cuyas opiniones, creencias, descubrimientos o experiencias son presentadas en publicidad.

16. En efecto, el artículo 8.2 de la LRCD señala lo siguiente: "configuran actos de engaño la difusión de publicidad testimonial no sustentada en experiencias auténticas y recientes de un testigo". 
Y esto tiene sentido, pues podríamos confiar mucho en las declaraciones juradas, pero hay que reconocer que también podría ser una forma de "sacarle la vuelta" a la norma. Entonces, los anunciantes tienen que tener pruebas que acrediten efectivamente que se trate de una experiencia auténtica y reciente de testigo.

El uso de influencers como testigos en la publicidad de los anunciantes es completamente lícito y la carga de probar que dicho personaje tuvo una experiencia auténtica y reciente con el producto promocionado, recae en el anunciante, no en el influencer.

\section{VI. ¿EL INFLUENCER VA A SER SANCIONADO CON HASTA 700 UIT?}

El responsable del contenido de la publicidad comercial siempre es el anunciante ${ }^{17}$, de conformidad con lo dispuesto en el artículo 23 de la $\mathrm{LRCD}^{18}$. Entonces, la única forma en la que un influencer sea responsable del contenido de la publicidad comercial es que sea un anunciante, es decir, únicamente en el caso que el influencer desarrolle su propia marca y difunda publicidad con el objeto de generar transacciones comerciales a su favor ${ }^{19}$.

Entonces, ¿qué pasa cuando el influencer es un soporte publicitario - a través de su cuenta de red social- para promocionar marcas de terceros o es utilizado como testigo en publicidad testimonial? No podría ser considerado jamás como anunciante. En estos casos el anunciante es la empresa que los contrata para que les hagan publicidad comercial a través de sus cuentas y/o como testigos fuera de ellas.

Con esto nos debería quedar claro que únicamente el influencer puede ser sancionado por el contenido de la publicidad si es anunciante, a la vez, de sus propios productos o servicios. De este modo, si se usa al influencer como testigo en publicidad de producto o servicio de un tercero o a través de su cuenta de red social para difundir publicidad a favor de determinado anunciante, jamás calificará como anunciante, por lo

17. "El anunciante es quien tiene la facultad de cesar en la actividad publicitaria y a obligación de rectificar cuando resulte procedente (...). Puede ser anunciante toda persona natural o jurídica (pública o privada) que tenga la capacidad de obrar requerida al efecto por las normas que resulten aplicables -civiles, mercantiles, administrativas- según su naturaleza. El dato específico y jurídicamente relevante, para ser un anunciante, es que se realice la publicidad en interés de la persona de que se trate. Se trata, por tanto, de una condición de carácter fáctico.

(...)

El anunciante es el interesado en la realización de la publicidad y, en consecuencia, el dueño de la comunicación publicitaria".

Manuel Santaella López, Derecho de la Publicidad (Madrid: Civitas Ediciones, 2003), 136 -137.

18. Artículo 23․- Asignación de responsabilidad.-

23.1.- La responsabilidad administrativa que se deriva de la comisión de actos de competencia desleal a través de la publicidad corresponde, en todos los casos, al anunciante.

23.2.- Es también responsable administrativamente, en cuanto le corresponde y de manera individual, el medio de comunicación social, por la comisión de actos de competencia desleal que infringen normas de difusión que regulan, condicionan o prohíben la comunicación de determinados contenidos o la publicidad de determinados tipos de productos. Esta responsabilidad es independiente de aquélla que corresponde al anunciante.

23.3.- Adicionalmente, corresponde responsabilidad administrativa a la agencia de publicidad cuando la comisión de actos de competencia desleal se genere por un contenido publicitario distinto de las características propias del bien o servicio anunciado. Esta responsabilidad es independiente de aquélla que corresponde al anunciante.

19. En efecto, el artículo 59 de la LRCD define al anunciante de la siguiente forma:

"Anunciante: a toda persona, natural o jurídica, que desarrolla actos cuyo efecto o finalidad directa o indirecta sea concurrir en el mercado y que, por medio de la difusión de publicidad, se propone: i) ilustrar al público, entre otros, acerca de la naturaleza, características, propiedades o atributos de los bienes o servicios cuya producción, intermediación o prestación constituye el objeto de su actividad; o, ii) motivar transacciones para satisfacer sus intereses empresariales;" 
tanto, no es responsable del contenido ni de la veracidad de las alegaciones publicitarias que utilice a favor del tercero anunciante. El único responsable en estos casos es la marca que hace publicidad haciendo uso del influencer.

Si este personaje es utilizado para promocionar determinado producto o servicio a través de su cuenta de cualquier red social, a lo mucho puede ser responsable si se le considera un medio de comunicación social ${ }^{20}$. Sobre el particular, consideramos que un influencer sí puede ser considerado un medio de comunicación social cuando hace publicidad para una empresa desde su cuenta de una red social, pues presta este servicio al anunciante y la norma es clara en señalar que es medio de comunicación social toda persona, natural o jurídica, que brinde servicios en cualquiera de las formas a través de las cuales es factible difundir publicidad — una de ellas, el internet— ${ }^{21}$.

Así, si el influencer es un medio de comunicación social cuando es contratado para hacer publicidad desde su cuenta de red social, únicamente sería responsable por cualquier infracción a una norma de difusión, mas no por el contenido del anuncio, en virtud de lo establecido en el artículo 23.2 de la LRCD, que señala "Es también responsable administrativamente, en cuanto le corresponde y de manera individual, el medio de comunicación social, por la comisión de actos de competencia desleal que infringen normas de difusión que regulan, condicionan o prohíben la comunicación de determinados contenidos o la publicidad de determinados tipos de productos. Esta responsabilidad es independiente de aquélla que corresponde al anunciante". - - el subrayado es nuestro-.

De acuerdo con nuestra LRCD, norma de difusión es toda norma referida a las características, modalidades y prohibiciones de la divulgación al público de la publicidad ${ }^{22}$ - cabe señalar que aquí no encaja la infracción al principio de

20. El inciso f del artículo 59 de la LRCD define de la siguiente manera al medio de comunicación social:

"Medio de comunicación social: a toda persona, natural o jurídica, que brinde servicios en cualquiera de las formas a través de las cuales es factible difundir publicidad, ya sea de manera personalizada o impersonal, en el territorio nacional, por medios tales como correspondencia, televisión, radio, teléfono, Internet, facsímil, diarios, revistas, afiches, paneles, volantes o cualquier otro medio que produzca un efecto de comunicación similar;"

21. Santaella señala sobre los medios de publicidad lo siguiente:

"el medio, como el anunciante y la agencia de publicidad, puede ser una persona natural o jurídica. Ahora bien, a diferencia de estos últimos, la LGP precisa que el sujeto-medio puede ser una persona (natural o jurídica) pública o privada.

(...)

La finalidad esencial, que constituye la auténtica nota distintiva del medio de publicidad, es dedicarse de manera habitual y organizada a la difusión de publicidad. En efecto, el medio supone en el proceso de la comunicación publicitaria un importante eslabón en cuanto es él quien hace posible, en definitiva, la comunicación pública que supone la publicidad.

El inciso final de la decisión legal, "a través de los soportes o medios de comunicación social cuya titularidad ostenten", alude a una realidad que diversifica los medios de publicidad en dos tipos fundamentales: los medios publicitarios que lo son exclusivamente (a los que la LGP denomina "soportes") y los medios de comunicación social en general que difunden, al lado de su propio contenido informativo, mensajes publicitarios."

Manuel Santaella López, Op. Cit., 139-140.

22. Artículo 58.- Definiciones

(...)

g) Norma de difusión: a toda norma referida a las características, modalidades y prohibiciones de la divulgación al público de la publicidad, con excepción de aquéllas referidas a la ubicación física de anuncios, las cuales tienen finalidad de orden urbanístico y no de regulación del mensaje publicitario; 
autenticidad ni a ningún otro principio como erróneamente señala el proyecto de guía-. Un ejemplo de norma de difusión son las prohibiciones establecidas por norma para la difusión publicitaria de determinados productos, como la que prohíbe la difusión publicitaria de productos de tabaco a través de la publicidad comercial difundida a través de la televisión de señal abierta — Ley 28705-.

Un ejemplo real de lo antes señalado, lo tenemos en el escándalo mediático que se desató contra la empresa Philip Morris, que generó la suspensión de su campaña publicitaria en la que utilizaba influencers para incentivar la adquisición de su nuevo cigarrillo electrónico "IQOS" — que contenía tabaco-23. En el Perú, estaría prohibido difundir ese tipo de publicidad y sería sancionada por infracción al principio de legalidad —artículo 17 de la LRCD—24. En este caso, existiría una responsabilidad por parte del anunciante como también una independiente para el influencer, pero únicamente por haber infringido la norma de difusión antes comentada y si es que dicha publicidad se difundió a través de la plataforma social del influencer, toda vez que únicamente en ese caso calificaría como medio de comunicación social.
Con todo lo anterior, si el influencer es utilizado como testigo en publicidad testimonial del anunciante, fuera de su cuenta de red social, el único que será responsable por el contenido de dicha publicidad será el anunciante. El influencer no tendrá responsabilidad alguna. Así se infrinja una norma de difusión, pues no calificaría como medio de comunicación social, mucho menos como agencia de publicidad, que eso sí es lo que nos genera mayores dudas, pues la única forma en la que pueda ser considerado el influencer una agencia de publicidad, es que brinde servicios de diseño, confección, organización y/o ejecución de anuncios. Difícil, pero no imposible. Lo cierto es que, en ese caso, tampoco va a ser responsable por cualquier aspecto vinculado a la oferta del anunciante, solo será responsable por el contenido publicitario distinto de las características propias de la oferta que se anuncia - por ejemplo, será sancionado si el anuncio infringe el principio de adecuación social por incentivar actos de discriminación-.

Por todo lo antes expuesto, podemos ir concluyendo que las posibilidades que se le sancione al influencer con 700 UIT son menores por no decir inexistentes, pues ello solo podría suceder si son, a la vez, anunciantes, y si su publicidad infringe gravemente lo dispuesto en la LRCD -

23. «Philip Morris suspende una campaña con 'influencers'», Diario El Periódico, acceso el 29 de mayo de 2019, https://www.elperiodico.com/es/extra/20190513/philip-morris-suspende-una-campana-con-influencers-7452019.

24. "El artículo 17 de la $L R C D$ establece que los actos contrarios al principio de legalidad "consisten en la difusión de publicidad que no respete las normas imperativas del ordenamiento jurídico que se aplican a la actividad publicitaria". Agrega la propia $L R C D$ que "constituye una inobservancia de este principio el incumplimiento de cualquier disposición sectorial que regule la realización de la actividad publicitaria respecto de su contenido, difusión o alcance".

En primer término, debe destacarse que la mención "legalidad" no puede ser empleada para argumentar que el principio se circunscribe únicamente a los casos de violación de normas de rango legal. Esta interpretación se encuentra apoyada por la precisión referida al incumplimiento de cualquier disposición sectorial. En según término, cabe destacar la precisión que efectúa la $L R C D$ al señalar que las normas cuyo incumplimiento importa la contravención del principio de legalidad, son las referidas a la actividad publicitaria.

Como el lector podrá advertir, estamos frente a un principio que habilita a la autoridad a sancionar una gran cantidad de supuestos diferenciados (...)".

Alex Sosa y Gustavo Rodríguez, Con licencia para anunciar. Un tratado del Derecho Publicitario en el Perú (Lima: Themis, 2014), 113. 
en el Perú son pocos los influencers que tienen su propia línea de productos y califican como anunciantes-; $y$, por otro lado, no tenemos un solo antecedente en el que se haya sancionado con 700 UIT a un medio de comunicación social o agencia de publicidad $^{25}$.

\section{TIPS PARA USAR INFLUENCERS}

Como ya lo hemos explicado en los puntos anteriores, el anunciante es el responsable del contenido de la publicidad comercial, no el influencer. De este modo, si se le utiliza como testigo en publicidad de un tercero anunciante, este último será responsable de todas las delegaciones objetivas $y$, por ende, comprobables que emita el influencer en el anuncio. Asimismo, si se usa al influencer y su cuenta de red social para hacer publicidad, el responsable del contenido también será la empresa anunciante que se beneficia con los comentarios, unboxing o cualquier acto que realice dicho personaje con la marca que lo contrata.

Así que los anunciantes deben tener mucho cuidado en el uso de influencers dejándolos libres a decir lo que venga de su inspiración. Si le dan una total libertad al influencer para que en virtud de su inspiración diga lo que quiera sobre su producto, el anunciante se corre un riesgo alto de infracción, toda vez que el influencer no va a ser responsable de absolutamente nada de lo que diga si es que es objetivo por su carácter comprobable, por el contrario, el anunciante será el único responsable frente al INDECOPI respecto de dichas afirmaciones.

\section{Tip $\mathrm{N}^{\circ}$ 1: mantener bajo control al in-} fluencer.

El responsable va a ser siempre el anunciante y no el influencer ya que se le está pagando a este último por hacer publicidad a favor de la marca, lo cual le va a reportar un beneficio en el nivel de persuasión de la comunicación. En ese sentido, una de las primeras tareas que tienen que hacer los anunciantes si van a hacer uso de los influencers es mantener el control de todo lo que el influencer va a decir o hacer. No lo pueden dejar en total libertad -al menos, no lo recomendamos. La "creatividad" puede ser traicionera-

En este punto toman importancia los guiones y contratos. $Y$ es que hay influencers que son más experimentados o están mejor asesorados que otros. A un novel influencer quizás los anunciantes le puedan poner un guión, pero a los que tienen experiencia o más trayectoria o cuentan con asesoría va a ser más difícil. Sin embargo, es importante que el anunciante posea el control, porque así "se curan en salud" frente a cualquier contingencia con la autoridad o en el peor de los casos, dejan constancia de que le indicaron expresamente qué cosas no podía decir el influencer, con lo cual pueden repetir contra él frente a cualquier sanción por infracción a la LRCD — dejando todo ello bastante claro en el contrato, obviamente-y obviamente, pueden apuntar a solicitar un atenuante en la graduación de la sanción.

Por todo lo antes señalado, es siempre importante elaborar un contrato, tener pautas por escrito, o al menos, dejarle bien claro - de forma expresa- al influencer qué es lo que no puede decir o ponerle límites a los comentarios que pueda hacer sobre el producto - por ejemplo, no compararlo con el producto de la competencia-. Esto posiblemente no sea útil dentro de un procedimiento ante el INDECOPI, toda vez que la autoridad sancionará de forma objetiva al anunciante por las alegaciones inexactas o engañosas que pueda realizar el influencer, sin embargo, servirá para repetir contra el influencer y aplicarle las penalidades que correspondan por contrato.

25. Con todo lo expuesto en el presente apartado, nos debe quedar claro que, si el influencer es utilizado como testigo en publicidad testimonial del anunciante, fuera de su cuenta de red social, el único que será responsable por el contenido de dicha publicidad será el anunciante. El influencer no tendrá responsabilidad alguna. Así se infrinja una norma de difusión, pues no calificaría como medio de comunicación social, mucho menos como agencia de publicidad. 


\section{Tip $\mathrm{N}^{\circ}$ 2: el uso de hashtags.}

El uso de hashtags en la publicidad de influencers no es un invento peruano, esto ya se venía utilizando en otros países. $Y$ es que es importante usar términos que permitan identificar el carácter comercial de las comunicaciones de los influencers a los consumidores. La clave, al parecer, está en el uso de hashtags \#publi, \#publicidad, \#ad, \#advertisement, etc; indicadores que permitan de alguna manera entender a los consumidores que la comunicación a la que están expuestos es patrocinada por una marca anunciante. Este punto es uno de los que más ha sido cuestionado del proyecto de guía del INDECOPI, pues en el mismo señala que solo se podría indicar \#publicidad o \#publicidadcontratada, pues a decir del INDECOPI, las abreviaturas no trasladarían la información necesaria para los consumidores. Nosotros discrepamos abiertamente de esa posición, pues refleja la falta de conocimiento de la autoridad sobre el uso de redes sociales de los consumidores.

El proyecto de guía recomienda que en los casos en los que no quede claro que la comunicación del influencer no sea comercial, puede usar hashtags como \#publicidad o \#publicidadcontratada la cual debería consignarse en un lugar donde sea fácilmente identificable y entendible, tomando en consideración algunas interesantes recomendaciones, donde algunas parecen obvias y otras completamente innecesarias por exceso. Las detallo a continuación con mis comentarios:

a) Recomienda algo tan obvio como: "Colocar la etiqueta en un lugar visible para el consumidor".

b) Recomienda evitar colocar el hashtag al final de la publicación, es decir, después de la opción "ver más", contraviniendo de este modo lo dispuesto en el artículo 21 de la LRCD que exige a la autoridad hacer un análisis integral y superficial de la totalidad del anuncio.

c) Recomienda evitar colocar la etiqueta al final del video, pues no todos los consumidores terminan de ver el mismo. En esta re- comendación vuelve a contradecir la LRCD, pues la autoridad está obligada a hacer un análisis integral y superficial de la totalidad del anuncio, de acuerdo con el artículo 21 de la LRCD. Además, nos preguntamos: ¿es culpa del anunciante que el consumidor no termine de ver el video?

d) Recomienda evitar colocar el nombre del anunciante mezclado con la etiqueta; por ejemplo, "nombredelanunciantepublicidad". No queda claro por qué, si al hacerlo, el influencer está dejando claro que está haciendo publicidad.

e) Recomienda evitar mezclar la etiqueta con gran cantidad de otros hashtags, restando visibilidad e importancia a la comunicación. En este punto nos preguntamos: ¿por qué no? ¿qué estudio establece que le resta visibilidad? Todo lo contrario, esta recomendación solo deja en evidencia la falta de especialidad de la autoridad respecto del funcionamiento de las redes sociales $y$, sobre todo, desconocimiento sobre cuál es el objeto del uso de hashtags.

f) Recomienda colocar la etiqueta en idioma castellano. En este punto resalta la importancia de primero conocer cómo se desarrolla este tipo de publicidad antes de hacer algún tipo de recomendación. Hace años que se usa la etiqueta \#ADV o \#AD para diferenciar la publicidad y los consumidores lo entienden.

Luego señala que no se pueden usar abreviaturas, con lo que limita y obliga prácticamente a los anunciantes a usar los hashtags \#publicidad o \#publicidadcontratada "ensuciando" su comunicación comercial. Esto es un claro exceso, pues no es tan difícil que un consumidor al ver \#publi entienda que es publicidad comercial.

Un exceso adicional de la referida guía es indicar que:

"(...) la comunicación de la existencia de relación material debe ser independiente de las herramientas que brinda de manera pre- 
determinada la red social. Todo ello debido a que, las funciones que ofrece la red social, para comunicar la relación comercial entre el anunciante y el influencer, no supone suficientes garantías de que sea un medio efectivo para la exteriorización del mensaje. Entonces, en caso las redes sociales requieran que se utilicen sus herramientas, el influencer debería complementarlas con mejores prácticas como el uso de hashtags."

Es decir, no importa si las redes sociales desarrollan una solución al "gran problema" de la publicidad encubierta. Igual se deben consignar los hashtags. No hay que perder la perspectiva, no olvidemos que lo que se busca es que el consumidor reconozca la naturaleza comercial que supuestamente está en riesgo, el objetivo no es arruinar la publicidad comercial y menos creer que el Estado siempre es el mejor posicionado para solucionar los problemas.

\section{Tip $\mathrm{N}^{\circ}$ 3: el uso de instastories y live stream para hacer publicidad con influencers.}

El 6 de noviembre de 2019, la Federal Trade Commission-FTC publicó una guía de recomendaciones para influencers ${ }^{26}$ bastante didáctica que el INDECOPI podría utilizar como modelo para la versión final de su guía, pues la idea es que sea bastante amigable para un público no especializado en Derecho, que son los que finalmente hacen uso de los influencers día a día.

Sin perjuicio de lo anterior, es importante detallar que varias de las recomendaciones que tiene dicho documento han sido criticadas en este artículo, así que es muy probable que el INDE-
COPI no las modifique al sentirse "respaldada" por un documento de la autoridad norteamericana. Así que rescataremos una de las recomendaciones que nos pareció una de las más interesantes: si se va a hacer uso de publicidad de influencers a través de instastories, la indicación de que se trata de un anuncio comercial debe estar tanto en el audio como escrito en el mismo, pues varios consumidores ven los instastories sin sonido. Asimismo, en el caso de videos "en vivo", hay que indicar constantemente que dicha grabación es patrocinada.

De nuevo, nos preguntamos qué culpa podría tener el anunciante de que un consumidor desee ver una historia de Instagram sin sonido o si se une a la mitad de una transmisión en vivo. Sería importante poder conocer cuál es el fundamento legal de dicha recomendación, toda vez que recordemos que el análisis que debe realizar la autoridad de la publicidad es integral, por lo que, si el anunciante cumplió con advertir que se trata de publicidad el uso de un influencer, ello debería bastar para que no sea considerado publicidad encubierta.

\section{CUANDO EL INFLUENCER ES A LA VEZ EL ANUNCIANTE}

Como hemos comentado a lo largo de este trabajo, solo cuando el influencer es a la vez el propio anunciante de sus productos - esto es, hace publicidad a favor de sus propios intereses- es completamente responsable del contenido objetivo de sus anuncios, el cual debe sujetarse a lo establecido por el principio de veracidad - actos de engaño- $-{ }^{27}$ y el resto de las modalidades desleales contenidas en la LRCD.

26. https://www.ftc.gov/system/files/documents/plain-language/1001a-influencer-guide-508_1.pdf.

27. "Siendo que la principal batalla por el mercado se libra en la mente de los consumidores, y teniendo los mensajes publicitarios en la actualidad un poder de captación gigantesco, el Derecho de la Competencia Desleal prohíbe que a los fines de la captación de clientes los mensajes publicitarios sean engañosos, pero no sólo en protección de los consumidores -objeto de protección con el que aquí se superpone con el Derecho del Consumidor-sino para proteger al resto de los competidores y la transparencia en el mercado. Ello así, pues un anunciante que utiliza un mensaje engañoso está desviando clientela a su negocio en forma artificial, perjudicando al resto de los comerciantes y dañando la transparencia a la que propende el Derecho de la Competencia Desleal."

Guillermo Cabanellas De Las Cuevas, Pablo Palazzi, Andrés Sánchez y Diego Serebrinsky. Derecho de la Competencia Desleal (Buenos Aires: Editorial Heliasta S.R.L., 2014), 360. 
Estamos convencidos que el acto de engaño es el aspecto que más debería preocuparnos, en lugar de cuestionar si el uso de influencers en publicidad es una comunicación comercial encubierta o no. $Y$ es que, como ya hemos señalado, consideramos que en la mayoría de los casos esta estrategia publicitaria no es encubierta. No hay que ser muy inteligente para preguntarse $o$ al menos dudar de que si un influencer está hablando bien de la marca de un tercero, lo más probable es que haya recibido algún tipo de contraprestación para hacer ello. Pensar lo contrario, es creer que existen unicornios y que el mundo es perfecto.

Lo realmente peligroso lo podemos encontrar cuando el influencer en calidad de anunciante difunde información engañosa que puede distorsionar mercados o inducir gravemente a error a los consumidores o incluso atentar contra su salud.

Nos referimos al caso de la influencer autodenominada Rawvana. Esta chica se hizo bastante famosa en los últimos años con sus dietas veganas. $Y$ es que además de siempre mostrar una excelente figura, señalaba que la misma era producto de esta dieta. Todo el mundo quería ser como ella y tener su figura, así que empezaron a imitar sus supuestos hábitos alimenticios. Al darse cuenta de ello, vio una oportunidad de negocio y no tuvo mejor idea que hacer un libro con sus recetas y dietas veganas. Dicho libro terminó siendo un best seller. Como se imaginarán, empezó a generar bastante dinero hasta que, de pronto, se difundió una historia de Instagram en el que una amiga, sin que Rawvana se dé cuenta, la había grabado comiendo un trozo de pescado frito.

Al parecer, Rawvana no era tan vegana como decía ser. Esto generó una gran pérdida de seguidores, empezaron las publicaciones contra ella de parte de sus seguidores. Y razón quizá no les faltaba pues sus dietas eran bastante arriesgadas, sobre todo una que recomienda hacer ayuno tomando solo agua por 25 días. No sé qué especialista de la salud podría recomendar ello y no sé qué tan sano sea, pero el sentido común nos dice que algo así le puede hacer daño a cualquiera. Imagínense las personas que seguían con devoción las dietas de esta señorita. Qué grave riesgo a su salud.

Evidentemente, esto es un acto de engaño porque más allá del fraude que pueda hacer Rawvana por no ser vegana frente a los consumidores, lo cierto es que estaba comercializando productos, dietas, libros sobre la base de un estilo de vida que decía o replicaba que formaba parte de su día a día y era un completo engaño. Es decir, concurría en el mercado a través del engaño, desviando la demanda de los consumidores hacia su oferta sin competir sobre la base de la propia eficiencia de sus prestaciones.

Esto es peligroso no solo desde el punto de vista comercial o concurrencial por ser un acto de engaño, también hay un problema de infracción a las normas de protección al consumidor, pues hubo consumidores que se creyeron el cuento de la dieta vegana y compraron sus libros o siguieron sus dietas, las cuales tenían un costo y eran falsas.

En esa misma línea, otro caso bastante famoso fue el de la influencer Belle Gibson. Ella fue un poquito más allá. Alegó durante años que tenía cáncer en el cerebro y que una dieta la salvó. Esto generó una gran cantidad de seguidores y se convirtió en una influencer famosa, lo cual aprovechó a su favor creando una aplicación - que fue un boom hasta que fue retirada de Playstore-y un libro el cual incluso se agotó en su momento — se vendía por Amazon-. Pero ¿cuál era el problema? El problema es que dicha señorita nunca tuvo cáncer, por lo tanto, su libro y aplicación, era un completo fraude, un claro acto de engaño. Los tribunales europeos la sancionaron con 320 mil euros.

Otro caso bien controvertido lo tenemos con la página web "Goop" de la reconocida actriz Gwyneth Paltrow. Dicha página se vio envuelta en varios fraudes o en varios actos de engaño. Esta actriz vendía, por ejemplo, un parche que "te hacía sentir mucho mejor, te hacía mejor persona" y la forma en la que vendía estos parches era diciendo que se trataba de un parche hecho con el material del uniforme de los astro- 
nautas de la NASA — National Aeronautics and Space Administration-, lo cual era falso. Incluso representantes de la NASA salieron a desmentirla. Pero lo peor que pudo ofrecer al mercado dicha página fueron los "huevos vaginales". Aunque no lo crean, en su publicidad alegaban que, si usaban estos huevos vaginales, las mujeres iban a mejorar su salud sexual y un mayor placer al momento de tener relaciones sexuales, entre otros "beneficios". Como se imaginarán, esto era completamente falso y realmente peligroso para la salud de los consumidores. Como señalamos líneas arriba, al parecer nos estamos concentrando solo en la publicidad encubierta, cuando hay cosas mucho más graves que pueden generarse por el influencer ${ }^{28}$.

Entre otras cosas que se vienen discutiendo tenemos los casos de los "influencers que no son influencers". Nos referimos a los que compran seguidores. Esto es un secreto a voces entre los influencers, pero esto es completamente real. Existen agencias de publicidad que les venden seguidores a las empresas y, ¿cómo hacen eso? Fácil, usan bots. En una especie de bancos gigantes de celulares, los programan para seguir a determinada persona con perfiles que no existen. Son influencers fraudes que de un momento a otro generan que posean más de 1 millón de seguidores y claro, el problema lo encontramos cuando ese influencer utiliza esa cantidad de seguidores falsos y va a empresas anunciantes para ofrecerse como soporte publicitario, pues si es contratado, recibe una contraprestación sobre la base del engaño.
Claro, es un acto de competencia desleal si consideramos que el mercado de influencers está en constante movimiento. Que una marca se vaya con un influencer implica un contrato menos para otros influencers.

Como vemos, en el Perú, como en otros países del mundo, se han concentrado más en tratar de detener la supuesta publicidad encubierta de los influencers, cuando en realidad el problema del uso de esta herramienta publicitaria pueda estar en otros tipos de actos de competencia desleal que sí se podrían estar generando en el mercado.

\section{REFLEXIÓN FINAL}

El presente artículo ha buscado hacer un análisis crítico de todo lo que se viene hablando acerca de la publicidad de influencers, toda vez que siempre es importante que una posición vaya en contra de la corriente para pensar las cosas con mayor objetividad y no hacer lo mismo que hacen otros países. De este modo, se ha dejado constancia de la posición del autor al señalar que la publicidad de influencers no es otra cosa más que una nueva forma de hacer publicidad testimonial y que la posibilidad de que se trate de publicidad encubierta es bastante menor. Sin perjuicio de esta discusión, consideramos que se cumple el objetivo de dejar bastante claro que la posibilidad de que el INDECOPI pueda sancionar a un influencer con 700 UIT es casi inexistente. Solo podría suceder ello si a la vez es anunciante y el acto posee tal gravedad que merezca la sanción máxima que establece la LRCD.

28. Según Rojas y Figueroa, “(...) resulta necesario investigar y debatir la necesidad de imponer nuevas exigencias normativas, bajo la pretensión de dar mayor transparencia al mercado. Así, para un consumidor pueden existir factores externos o internos, tales como la autoestima o emociones, que motiven al consumidor a seguir a un influencer determinado, lo que podría generar un sesgo conocido como "anclaje" o "cascada de disponibilidad".

Así para el análisis conductual del Derecho, la falta de información hace que confiemos en las decisiones de los demás, suponiendo que ellos sí están informados. Lo anterior se debe en gran medida a las influencias reputacionales; es decir, que confiaos en la palabra de ciertas fuentes, tales como las provenientes de gente que admiramos, noticieros, políticos, etc. y generamos lo que se denomina "cascada de disponibilidad".

Carlos Rojas y Ana Lucía Figueroa, «Debe regularse el rol de los influencers en redes sociales? Una aproximación del análisis conductual de la normativa publicitaria peruana», en Análisis Psicológico del Derecho (Lima: Themis, 2018), 487. 